\title{
Research of Consumers' Online Choice Behaviors
}

\author{
Lu Zhao, Zhu Tao and Qin Peng
}

Nanchang Key Laboratory of material and structure detection Jiangxi University of Technology

\author{
Keywords: E-commerce; Customers' choice; Research of behaviors
}

\begin{abstract}
Nowadays, with the popularity of online shopping, there are more and more online shops with sellers from all around the country selling various kinds of goods on the Internet. Then, this paper mainly researches the principles which customers should follow while choosing and purchasing among so many goods and customers' choice behaviors, namely, what differences customers should observe while choosing snacks and foods, what are the most important properties that customers should pay attention to for different categories of food and what different concepts of choice that customers from different places have. As long as customers' requirement of choices is mastered, goods can be designed according to customers' preferences.
\end{abstract}

\section{Introduction}

With the rapid development of the Internet, manufacturers of various industries are driven to online sales. Online shops, such as Taobao and JD, are favored by the public. Although there are risks, online shopping is still favored by the public and it has already been deeply rooted in people's minds. With the constant development of the economy and the improvement of people's consumption level, people have increasing demands for the quantity and quality of snacks, the supply of which is also expanded from the traditional marketing channels to online shopping platforms with a rapid momentum of development. This paper mainly researches customers' choices of online shopping under the overall environment of e-commerce. This paper takes snacks as an example to study the impact of their different attributes and other factors, such as customers' occupation, income level and ages on customers' choice. Then, the paper summarizes the data of different attributes through investigation so as to get the conclusion. Finally, corresponding suggestions are provided to sellers according to data results so as to enable them package their goods according to customers' choice behavior and improve the harmony of online shopping.

\section{Basic Situation of Customers' Online Choice Behaviors}

Basic Situation of Questionnaire Survey. This questionnaire survey is at random. First, questionnaires are made and distributed online according to actual situation, and then these questionnaires are collected at an appointed time.. Finally, 200 valid questionnaires are collected.

Valid questionnaires are collected to integrate answers in the questionnaire so as to get the total amount and the proportion of each unit's base in the total, and finally, the table is made.

Basic Situation of Online Survey. This paper mainly gets the data from online survey and obtains investigation materials of data about customers' purchase choice recently from Baidu, Taobao and JD. Finally, 3281 data are collected.

\section{Customers' Own Factors Influencing Their Choices}

Influence of Income Level on Consumer Behaviors. It can be seen from the above investigation that income level is an important factor influencing consumer behaviors, and it can be seen from Fig. 1 that the income of those customers buying snacks is below 2,000 yuan or between 2,000 to 4,000 yuan, accounting form $37.8 \%$ and $41.7 \%$ respectively. It can also be seen 
from the table that purchase probability of customers whose income is between 4,000 to 20,000 decreases with the increase of income, so it can be concluded that high income earners are not so interested in buying snacks, so customers whose income is between 2,000 and 4,000 are the main consumer group of snacks, and this conclusion can be clearly shown in the figure below:

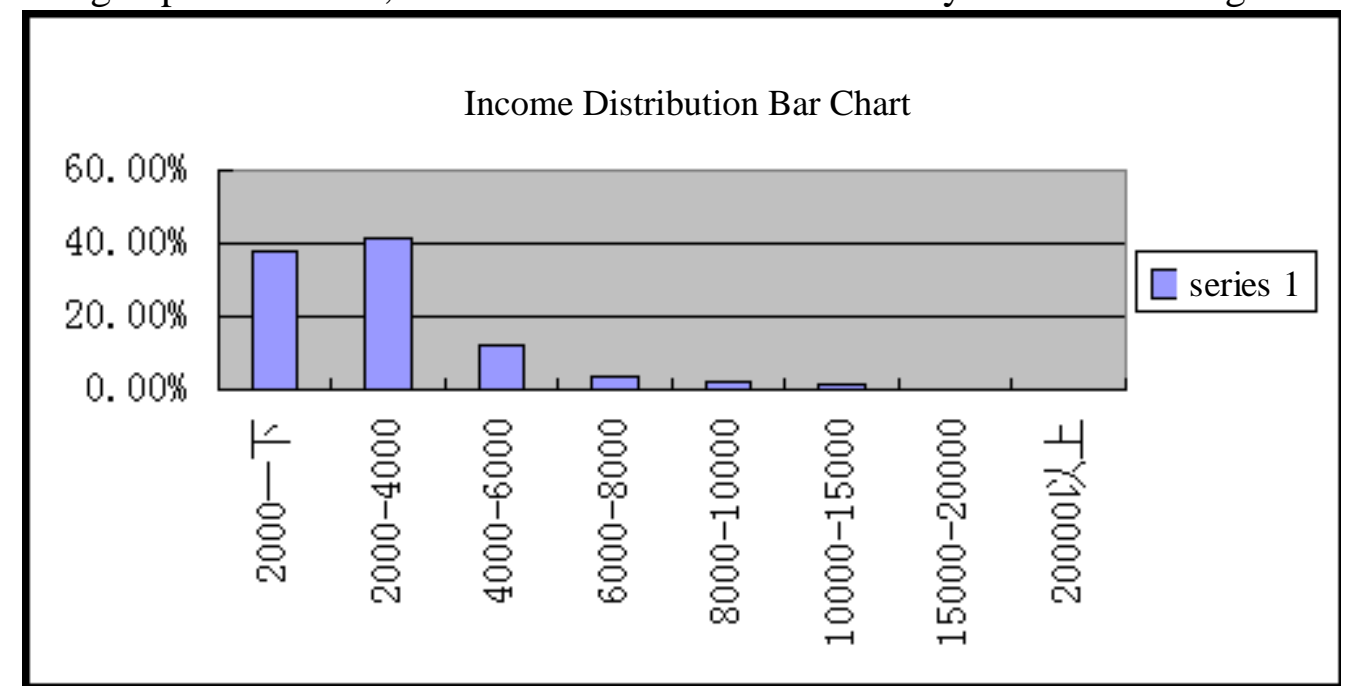

Fig. 1 Income Distribution Bar Chart Series 1

Influence of Occupation on Cons umer Behaviors. Consumers of snacks are mainly students and common employees. Students are the most consumers of stacks, accounting for $25.9 \%$ of overall consumers. Then, it is the common employees of enterprises, accounting for $25.3 \%$. It can be seen from the table that with the increase level of occupations and the freedom, consumption of stacks decrease, which is mainly because that students and the common employees of enterprises have more leisure time and their incomes are not high. These people are basically at the stage of meeting basic demands in life, such as food and clothing. While those with higher positions pay more attention to leisure and entertainment in addition to food and clothing, so common employees are still the main consumers of snacks. In order to more intuitively reflect the influence of job positions on the consumption of snacks, the following chart is drawn:

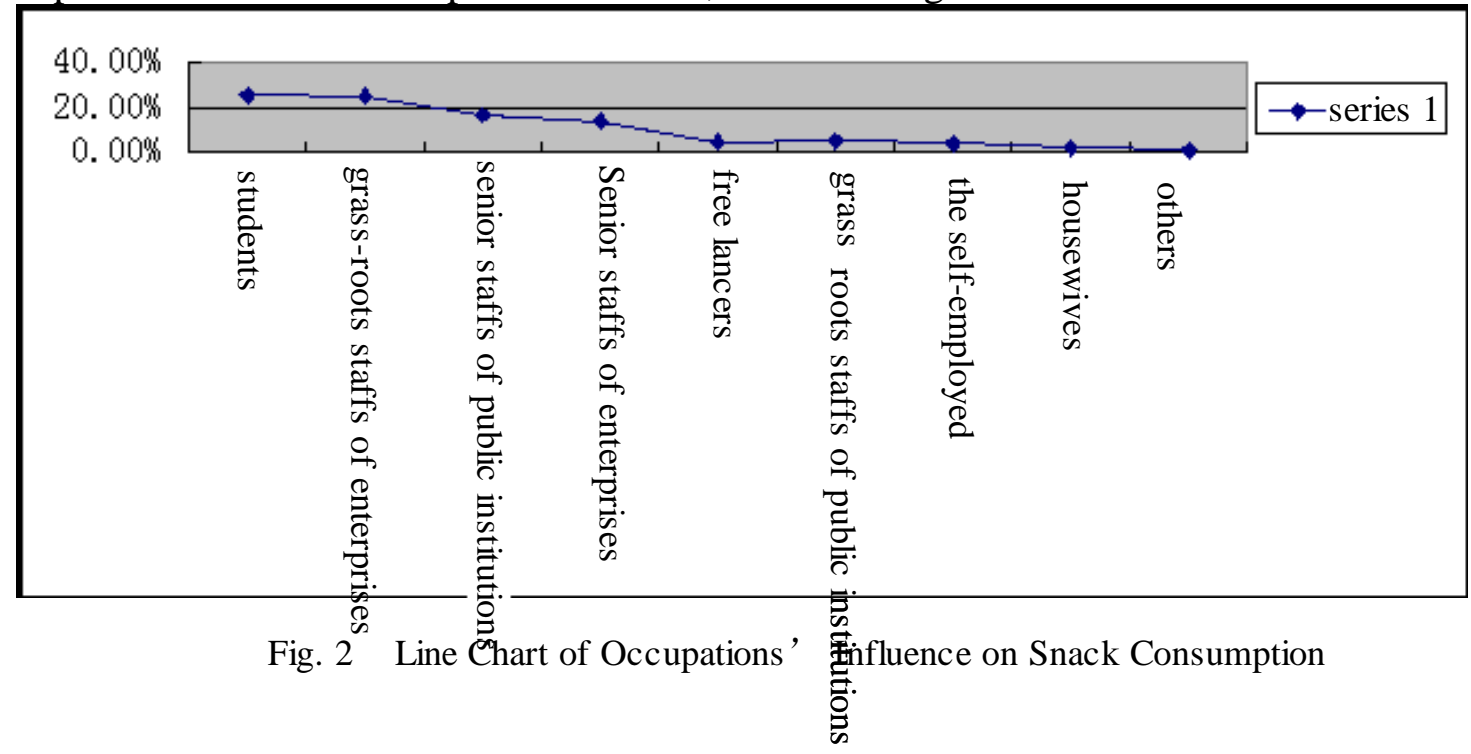


Influence of Age and Gender on Consumer Behaviors. Consumers' demands for products varies with the increase of age, and they need different various commodities at different stages of life. Customers of different genders have great different purchase behaviors., The following conclusion can be got through the above data and investigation.

First of all, there are far more females buying stacks than males, and in terms of genders, female consumers buying stacks account for $69 \%$, but male customers only account for $31 \%$. As shown in Fig. 3:

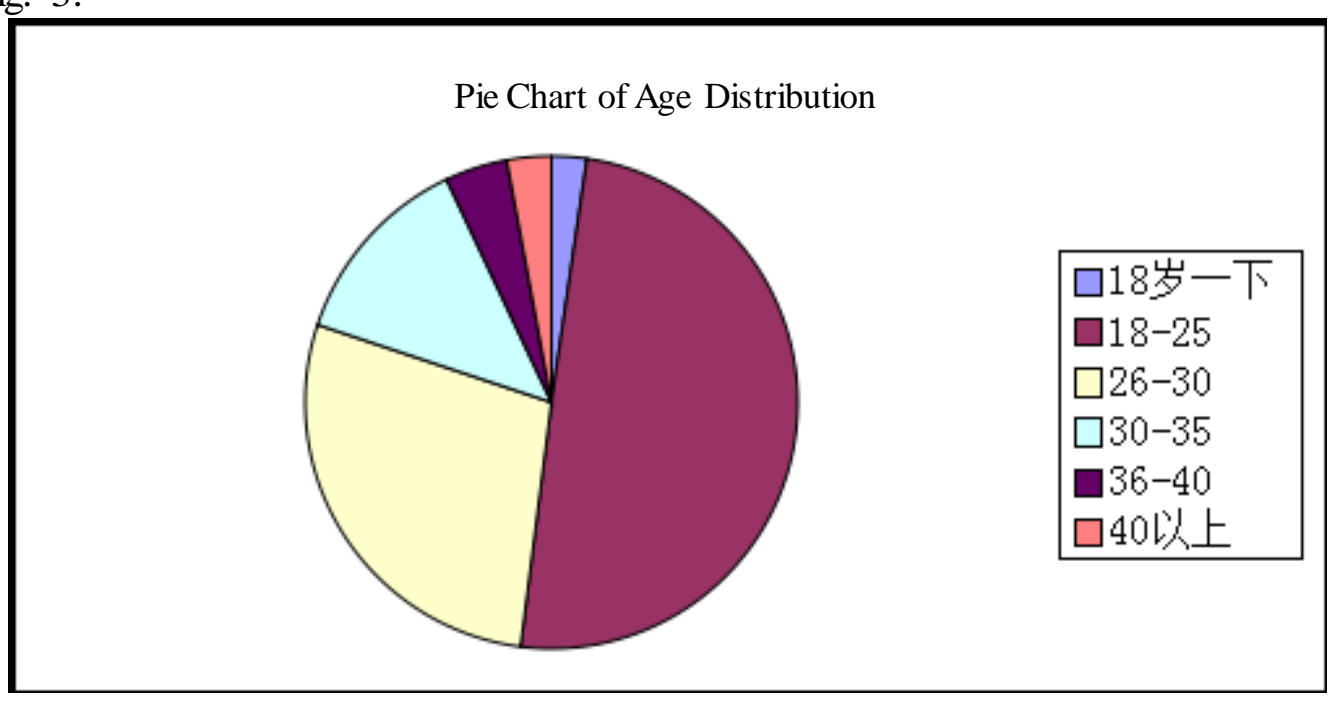

Fig. 3 Pie Chart of Age Distribution

Impact of Education on Consumer Behavions. Culture can be defined as an entire set of concepts which are common in a certain group, such as value, belief, preference and taste. Any single customer is in a particular society, and cultural factors have a deep influence on online consumer behaviors because it affects each individual and their mental activities through affecting all sectors and families in the society. Under different cultural background, people have different understandings of online shopping.

This paper studies the influence of education on consumer behaviors through data and investigation. It can be seen from Table 9 that undergraduates account for the highest proportion of $51 \%$ of stack customers, followed by vocational college students, which account for $30.4 \%$ of total customers.

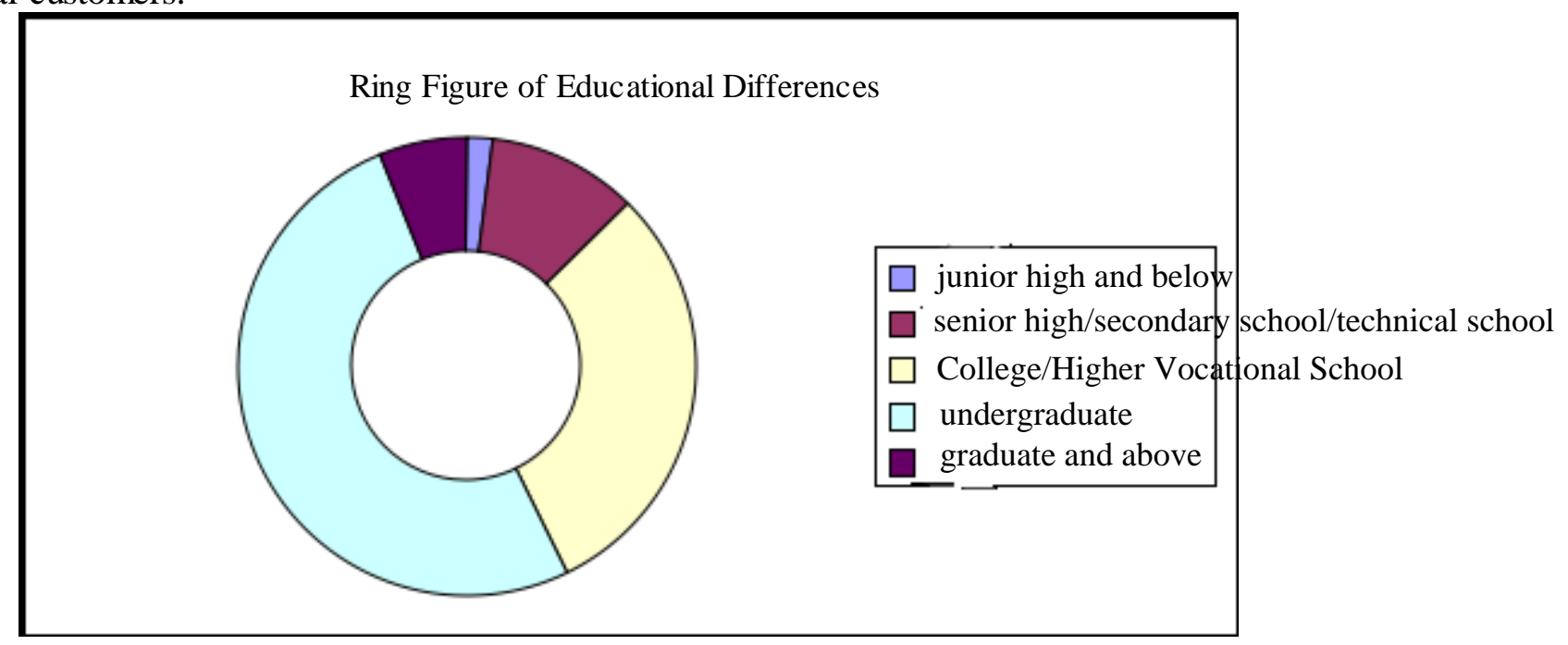

Fig. 4 Ring Figure of Educational Differences 


\section{External Factors Influencing Consumers' Choices}

Price. For online consumption, price is also the main factor influencing consumers. A considerable number of consumers choose online shopping because there are lower prices on the Internet for the same commodity, which is more appealing. If online shops have the same price as stores, then consumers are more likely to buy at stores. Therefore, online pricing is also the main means of competition for many online shops, and price is the main factor influencing consumers' choices.

Food Security. In recent years, consumers are more and more focused on food security, and the frequent food security problems cannot make consumers believe the quality of food while choosing commodities online shops. Therefore, food security is also a major factor influencing consumers' choices.

It can be seen from this survey that food security does not accounts for a higher proportion of stack commodities on the Internet with only $18.2 \%$ not exceeding the price proportion. Although stack consumers consider less about food security, it can also be seen that due to the various incidents about food security recently, stack consumers also have the awareness of food security. They will choose relatively safer food when the prices are relatively similar, and they will pay more attention to food security with the increase of their economic strength.

Sellers' Integrity. Sellers' integrity includes the quality of commodity description, service attitude and logistics speed. It can be seen from Table 2.11 that sellers' integrity accounts for $25.1 \%$, and compared with prices, customers are more concerned about sellers' integrity while choosing online shops. Thus, it can be seen that if an online shop has higher integrity, even if it has higher price, customers will choose it. With the improvement of customers' living standards, they have higher and higher requirements for materials. Thus, today's customers will generally choose good products rather than cheaper prices, and sellers' integrity becomes important at this historic moment.

Food Packaging. For online stops, it is not the entire work to make a certain commodity become unique, and the most important is to combine this characteristic with decisive factors that customers believe so as to attract customers and meet their urgent needs. Actually, this idea has been utilized by many online stores and clearly demonstrated on the food picture of these online stores. The color of food and background, the use of lighting and the choice of packing box are all examples in this regard.

Degree of Favorable Evaluation. Consumers can get to know the evaluation of this product through searching information and make the purchase decision after making comparison. Of course, they may also postpone or cancel the purchase behavior due to the problems in evaluation and selection, so at this time, consumers' purchase decision is at a standstill. Online shops cannot make any preparation for customers' purchase behavior because once customers make the purchase decision, all the rest procedures are completed in stores or other places, that is, payment, delivery of goods and arranging the place of delivery, etc.

Ways of Payment. In this investigation and research, ways of payment are also important factor influencing customers. $18 \%$ customers pay attention to the ways of payment, which is very important to customers because it cannot only guarantee customers' benefits, but also meet their mental demands.

The proportions of price, security, sellers' integrity, favorable evaluation, ways of payment and food packaging in customers are made into a chart so as to more intuitively get to know consumers' attention to relevant attributes, which is shown as below: 


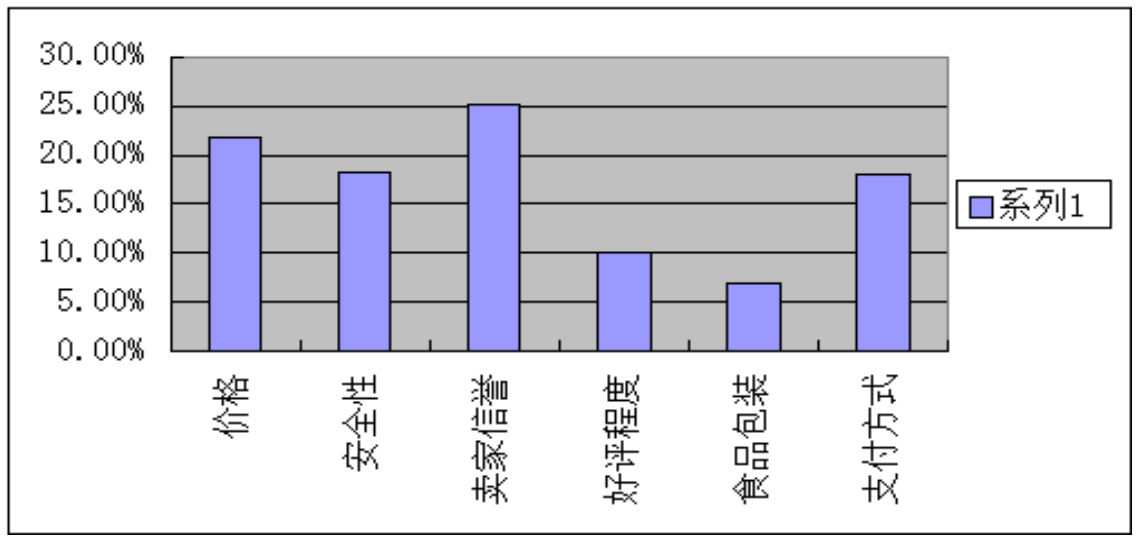

Fig. 5 Bar Chart of Proportion in Consumers' Heart

\section{Suggestions to Online Sellers}

It is the foundation for the survival and development of enterprises to research consumers' demands and master characteristics of consumer behaviors. Through some researches of consumer behaviors' characteristics, provide some methods and ideas to online retail industry to improve online sales, and particular attention should be paid to the several following aspects:

1. To make online shopping be more attractive, online retail shops should strengthen their own characteristics and provide good shopping environment for consumers.

2. At online shops, it can be seen that various online retails shops are in a fierce market competition, and there are a lot of online shopping platforms. Therefore, it is far from enough to make false increase of flow and volume of deals within a short time in order to stand out from numerous competitors. Starting from consumers, grasp the demands of female consumers aged 18-30 and the common employees of enterprises. As enterprise staffs join online shopping, the peak of online shopping also corresponds to the working hours of these people and free time will be a peak of online shopping. Therefore, online sellers can consider staffs' working hours while uploading new products.

3. It is the primary and key step for the success of online sales to choose products and services which are suitable for online sales characteristics. Online retail enterprises should provide suitable products according to customers' demands instead of selling products through the traditional retail method on the Internet. Online shops should consider whether their products are suitable to be sold on the Internet before carrying online retail activities.

4. Make flexible use of commodity pricing strategy. Online snack consumers have higher requirement for price. Income of customers buying snacks online is mainly 2,000 to 4,000, and they are mainly students and the common employees of enterprises. Therefore, for these customers without high income and still focused on food, clothing and price, snacks should have a price which is more close to customers and attract customers through exemption from postage, seasonal discounts and quantity discounts, etc.

5. To improve technology to ensure the safety of customers' information. The security of customers' information is a problem that consumers consider a lot. Online shops should ensure the security of consumers' personal information on technical aspect, which does not only safeguard customers' interests and rights, but also improves their integrity.

6. It is an important channel to improve the integrity of online shops to improve sellers' serving attitudes, make good after-sales services and choose a good logistics company.

7. The publicity of foods should be paid attention to. Even a perfect commodity still needs to be publicized constantly. The development of online shopping is obvious, but some online shops cannot catch up with the development pace of the Internet. Development indicates changes, and changes bring opportunities. Enough publicity should be made while cooperating with various 
media such as Wechat and Microblog, to achieve good effects without putting much effort. This is a good choice for many online snack sellers.

\section{Conclusions}

Currently, the annual turnover of the world's snack market is already more than $\$ 40,000,000,000$ with the increase speed more than $20 \%$ of other food, so snacks have a huge space for development in China. This paper studies factors influencing consumers' choice behaviors from two aspects: consumers' own factors and external factors. In terms of consumers' own factors, snack consumers are mainly aged 18-30 with their incomes between 2,000 and 4,000, and they are mainly students and common employees of enterprises. In terms of external factors, the most important is sellers' integrity, followed by price and security. From the report, suggestions are put forward for online sellers to help improve consumers' purchase demands.

\section{Acknowledgment}

This work was supported by Project on professional and characteristical construction of J iangxi province 2010 (Civil Engineering) and Project on the planning and construction of disciplines in Jiangxi University of Technology (Structure Engineering)

\section{References}

[1] Chen Yiwen, Ma Jiwei. Purchase Factors Influencing Consumers [J]. Progress of Ps ychology 2012, (1): 12-21.

[2] William Cusick. Get to Know What Consumers are Thinking [J]. Commercial Review of Beijing University, 2013, (4): 8-13.

[3] Tian Yu. Impact of Online Reputation on Consumers' Intention to Purchase [M]. Beijing: Electronic Industry Press, 2013.

[4] Meng Fanhua. Factor Analysis of Consumers' Online Shopping and Countermeasures [J]. China's Economic \& Trade Herald, 2010, (1): 24-33.

[5] Zhong Kai. Research of Online Consumers' Perception Value's Influence on Consumers' Purchase Intention [M]. Liao Ning: Mechanical Industry Press, 2013.

[6] Fu Yuan. Research of Platform-Type E-Commerce Agglomeration Mechanism [M]. Beijing: Posts \& Telecom Press, 2013.

[7] Tang Jun. Research of Consumers' Green Purchase Decisions Based on Preference of Product Attributes [M]. Beijing: Electronic Industry Press, 2010.

[8] Cen Wei. Research of Business Factors' Influence on Consumers' Choice Behaviors in C2C [J] Modern Business Trade Industry, 2009, (22): 14-22.

[9] Li Yufeng, Lv Wei, Hu Qihui. Research of the Influence of Product Utility and Hedonic Attributes on Consumers' Satisfaction [J]. Journal of Yunan University of Finance, 2011, (1):8-15.

[10] Wan Zhichao, Wang Yajie. Research of Consumers' Individualized Preferences Based on Product Attributes [J]. Journal of Beijing University of Posts and Telecommunications, 2013,(5):14-23.

[11]Der Junn Deng,On gender differences in consumer behavior for o nline financial transaction of cosmetics[J].Irish Journal,2013,(58):12-23. 